\title{
CAPA
}

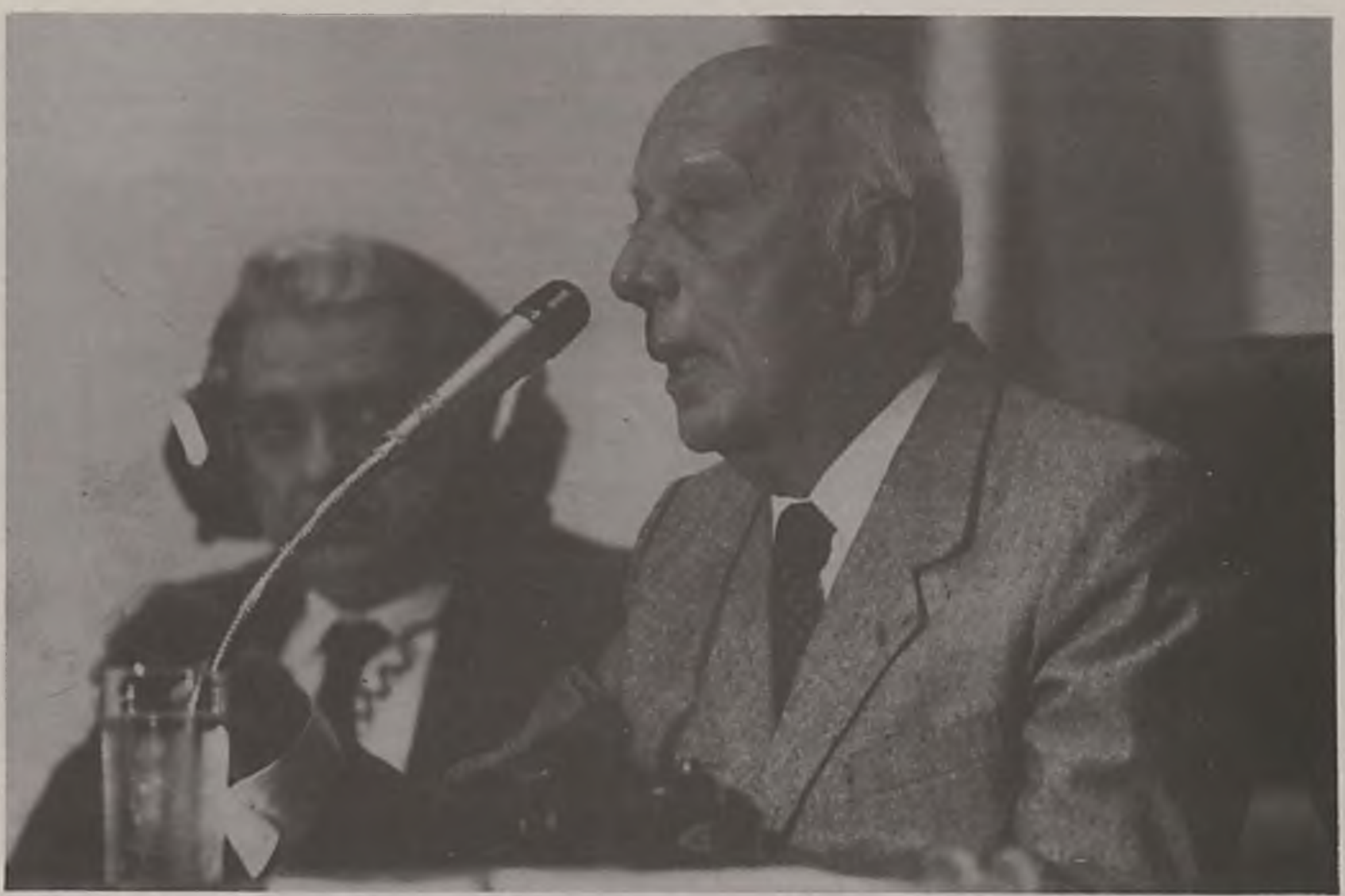

\section{Ulisses: a fé presidencialista}

Quero cumprimentar as outras autoridades que aqui se encontram e em nome da Constituinte, agradecer a esse simpósio a programação que aqui se desenvolve, sob o nome de Seminário Internacional sobre Presidencialismo e Parlamentarismo.

A todos aqueles que colaboraram, inclusive o governo brasileiro, para que isso fosse possivel, eu desejo centrar a minha palavra de agradecicmento, em nome dos constituintes, da Assembléia Nacional Constituinte, à pessoa do eminente ministro, antigo parlamentar, homem público também, tão respeitado, conhecido neste país, Aluizio Alves.
Desejo, em rápidas palavras, meus amigos, para não tomar o tempo daqueles que vão ouvir palavras mais sábias, mais procedentes, mais experientes, muito mais interessantes do que as minhas, dizer que eu agradeço, eu agradeço ao Ministro Aluizio Alves esta iniciativa, porque este problema da forma de governo é o problema modular, central, é a medula, é o centro de gravidade da futura Constituição, conseqüência da vida política deste país. Se nós tivermos a competência de fixar um regime que realmente produza as açōes administrativas, governamentais, estatais, em benefício do povo brasileiro, isso significará para a socieda- de um grande avanço que corresponderá à sua ardente expectativa.

Posso dizer, pelas informações que tenho, e as tenho numerosas, que este assunto transcende o âmbito hoje, dos eruditos, dos juristas, e dos políticos, da periferia, dos bairros. Já estas palavras não são esotéricas, enigmáticas, misteriosas: presidencialismo e parlamentarismo. Em debates que se realizam em todo o País, na televisão acompanho com muita atenção, um dado interessante, principalmente para os mestres estrangeiros que aqui se encontram, é que nós temos um programa que se chama Diário da Constituinte em todas as televisōes do país, e já man- 
damos fazer pesquisas, pesquisas das mais altas da opinião pública do país. O povo ouvindo, o povo acompanhando foi um extraordinário acontecimento de comunicação que até nos tem surpreendido.

Como sabem, e estão aqui no Congresso, este edifício é visitado diariamente por 4 a 5 mil pessoas. Regurgitantes de gente, os corredores, as salas criam, às vezes, até problemas para o ordenamento dos nossos trabalhos, no meu gabinete, nos gabinetes dos deputados. E o que é muito interessante são as camadas populares que aqui vêm. Crianças, domésticas, paraplégicos. As camadas, freqüentemente as mais populares, vêm aqui e vêm trazendo contribuição, trazendo memoriais, trazendo reivindicações, de forma que eu não tenho dúvida nenhuma de que, se depender deste banho da sociedade, desta colagem, acoplagem da sociedade con a Constituinte, sem dúvida nenhuma ela a traduzirá e tem condições para tal, porque não se isolou, não é uma torre de marfim, não está aqui isolada, nós temos a fiscalização e, diria, a pressão popular, as galerias cheias para acompanhar a elaboração deste documento fundamental, o pacto político da Nação.

Desejo dizer, e peço desculpas se estou tomando tempo, mas só mais alguns minutos, devo dizer que eu tenho a antiga convicção presidencialista. Entendo que é um dado cultural no Brasil, entendo que, de certa sorte, convida à meditação a circunstância de que o parlamentarismo, principalmente na Europa, evoluiu do sistema monárquico do rei, do principe; portanto, o detentor do poder não tem origem popular para o sistema parlamentar. Não é o caso do Brasil. O casso do Brasil é que nós tivemos precisamente o parlamentarismo como tínhamos o rei, quando tínhamos u'll imperador, pedro II. E, na República, a figura do imperador foi substituida pelo voto popular, com os defeitos que eu sei que existem, porque nós os temos procurado corrigir. Mas esta circunstância é interessante quando nós verificamos que até de certa forma os parlamentares estão evoluindo de um parlamentarismo para um presidencialismo, todo o sistema dual de governo. É o caso da França, que, do parlamentarismo ortodoxo, tem o presidente eleito. É o caso também de Portugal, onde isso também ocorre.

Desejo dizer, não estou falando de novidade nenhuma, que é uma das características, pelo menos do Brasil, a grande expectativa que se tem da solução dos pro- blemas por parte do poder público. Uma expectativa que acontece exagerada, que não devia existir, mas que existe. Nas cartas que se recebe para se resolver problemas, problemas até domésticos, há uma grande esperança, expectativa da população, desejo de resolver os seus problemas por via do governo e, principalmente, de quem represente o Estado, pessoalmente, qual seja o Presidente da República.

No Brasil, isso se demonstra constantemente. Vem o Papa, e surge o slogan: $\mathrm{Hei}$, hei, hei, queremos o nosso rei. $\mathrm{O} \mathrm{Pa}$ pa transformou-se em rei no Brasil. O Pelé, que é uma figura popular, é o rei, o rei do esporte, o rei. $\mathbf{E}$ temos outro rei também, que é o Roberto Carlos, o rei da canção. De maneira que estou trazendo aqui um enfoque popular. São plebiscitados: não dizem o presidentc Pelé e assim por diante. É o rei Pelé.

De forma que também gostaria de meditar que o presidencialismo que nós importamos dos Estados Unidos, principalmente pelo gênio de Rui Barbosa - o erro eu entendo que não é propriamente do parlamentarismo - vem da prática do parlamentarismo caudilhesco, parlamentarismo de César, existente no Brasil, que é diferente do dos EUA. Nos EUA, que de certa sorte nós podemos dizer ser um dos paises mais parlamentaristas do mundo, há o Congresso, há o episódio de Wil- son na criação das sociedades das Nações, por exemplo. Nós temos agora o que está acontecendo com Reagan, e podia aqui enumerar outros tantos exemplos, onde o Congresso realmente é Congresso, é parlamentarista, tem força, se contrapõe, freios e contrapesos, o que não aconteceu no Brasil. No Brasil, o Legislativo se acaudilhou, foi enfeudado pelo Executivo, dominado pelo Executivo, não firmou a sua independência. No Senado, por exemplo, em que herdamos as atribuições de aprovar altos funcionários, eu pergunto: qual é o Ministro do Supremo Tribunal que já foi recusado, nos 100 anos que vamos comemorar dentre em breve de república presidencialista no Brasil? Aconteceu, até recentemente, com Reagan, nos EUA; aconteceu com os episódios famosos conhecidos por Roosevelt, nos EUA. O Embaixador, houve um ou dois episódios, mas não foi pela questão do Embaixador, por problemas com o Executivo, um ou dois casos de embaixador recusado. Qual é o Ministro do Supremo ou do Tribunal de Contas recusado pelo Senado? De forma que, na verdade, tenho impressão de que, no Brasil se devia revigorar o Legislativo. O Legislativo devia ter condições de independência; aumentar os seus poderes; ter o poder; ter os temperos parla mentaristas; convocar ministros, inclusive nas Comissōes; o poder de fiscalização

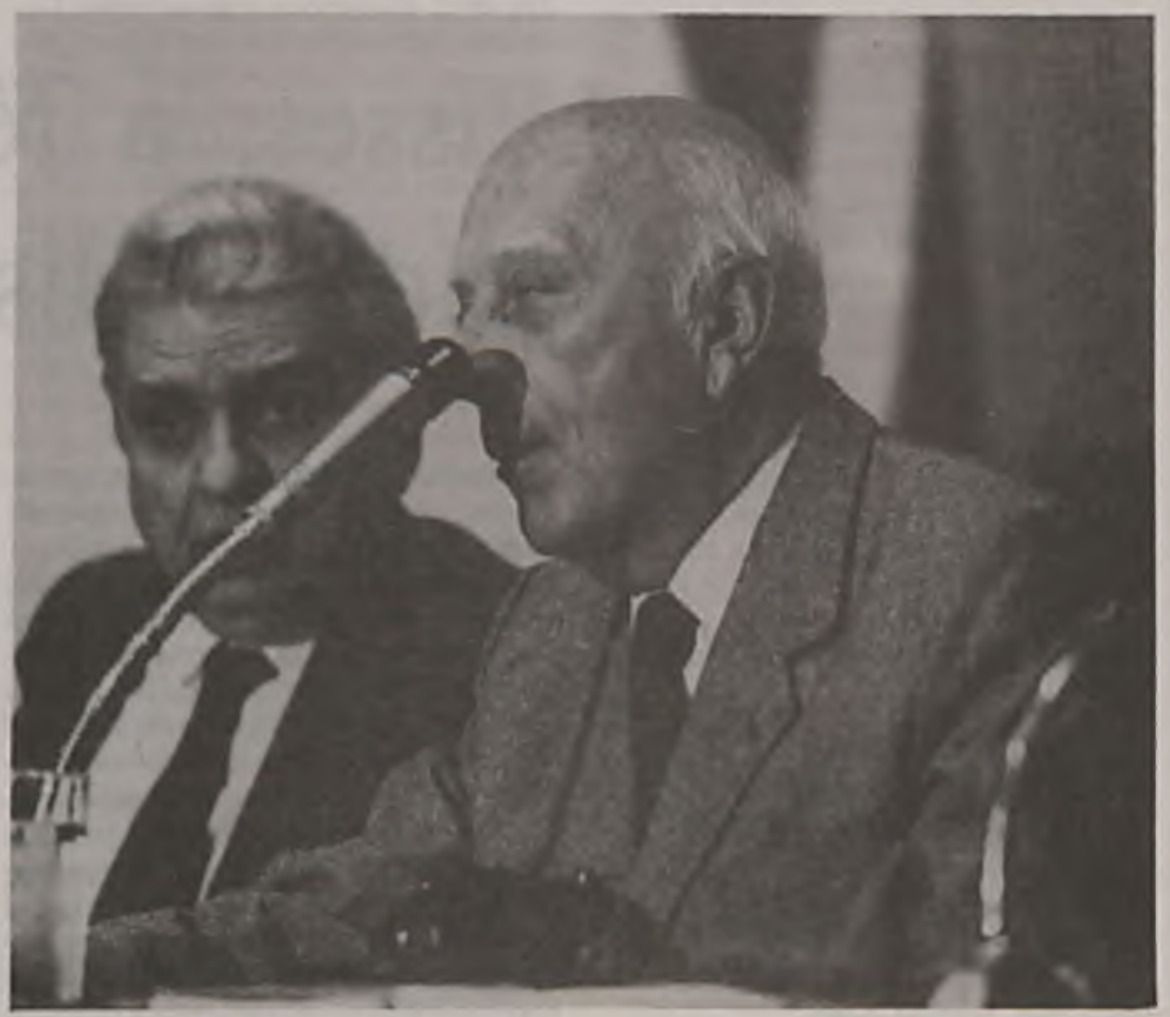




\section{CAPA}

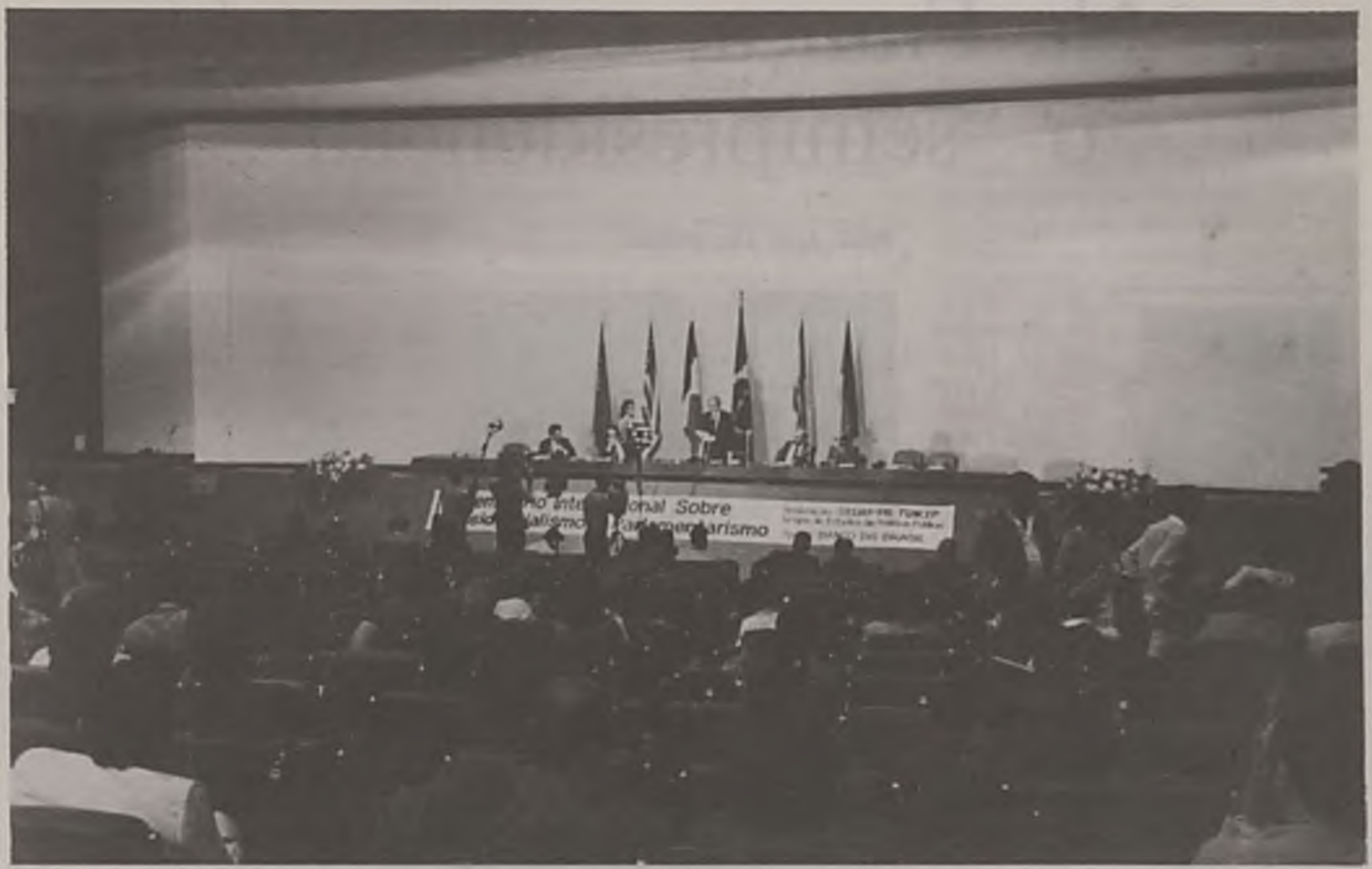

e fazer com que houvesse até o processo de responsabilidade e não responder em 30 dias. Se não puder em trinta dias, pedir o prazo de mais 30 dias, mas ser processado se não responder. Há pedidos de informações, que são uma arma extraordinária de fiscalização, há as comissões parlamentares de inquérito. Enfim, meus amigos, entendo que este dado que eu chamo cultural nào podia ser extirpado, a meu ver, de um momento para outro; eu teria muito receio da fórmula parlamentarista no Brasil. Poderíamos aí fazer um sistema como antes, com uma maior participação do Legislativo, e existem aí oito ou dez projetos, eu não vou tomar o tempo da casa a esse respeito.

O sistema parlamentarista, quer dizer, um sistema de partidos, é preciso ter partidos. O meu partido é praticamente o partido nacionalmente organizado no Brasil, assim mesmo ainda tem uma história recente. Praticamente, outros não existem. Em segundo lugar, projetar o parlamentarismo para os estados, porque se não se adotar o parlamentarismo nos estados, qualquer governador, concentrando os poderes, terá mais poderes do que o Presidente da República que divi- de o seu poder com o primeiro-ministro. Também, e isso reputo indispensável, que se emancipe a instância ou o setor burocrático do setor político; do contrário, a cada ministro que caia muda o Presidente do Banco do Brasil, muda o Diretor do Banco do Brasil, muda o Presidente do BNDES, muda o Presidente do Banco do Nordeste e, mais do que isso, nas fontes, por causa do Funrural. Eu nunca soube da importância do Funrural. Em São Paulo não há esse problema do Funrural, mas o Funrural derruba todo um Ministério, porque está lá na ponta, no lugar, na grande disputa de prestígio dos parlamentares deste partido ou de outro partido.

Enfim, meus amigos, eu desejo dizer o seguinte: eu tenho convicção, mas não sou teimoso, graças à Deus. Para servir ao meu país na altura da vida em que eu estou, eu tenho uma desimpedição total, estou inteiramente aberto, acho que as contribuiçōes daqueles que aqui estâo, principalmente parlamentaristas, são da maior valia, e eu estou certo de que a maioria dos constituintes deverão caminhar na direção certa. Mas devemos falar com franqueza, com sinceridade, porque o problema é da maior importância.

Eu quero renovar meu agradecimento, principalmente aos mestres que vieram dos seus paises nos ajudar a resolver este grave problema.

Muito obrigado.

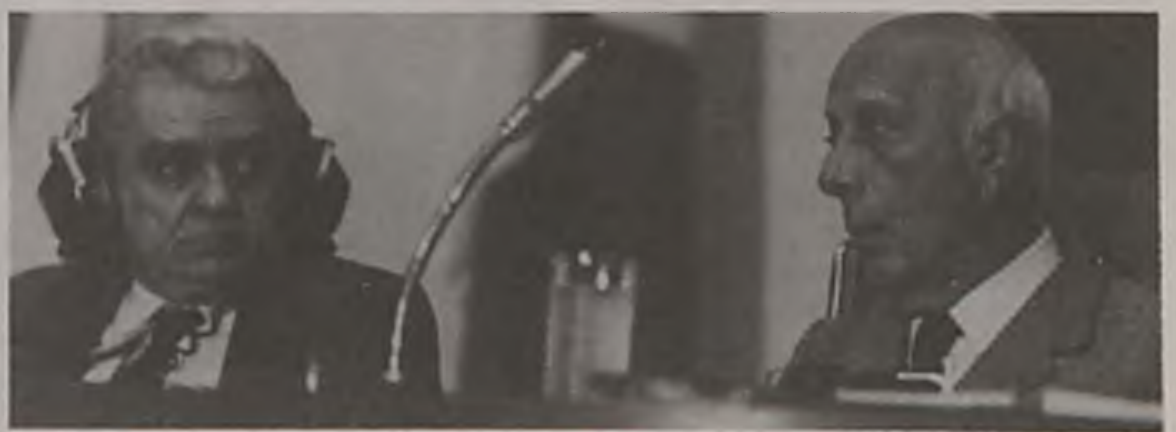

